\title{
“Que bicho é esse?”: descrição e vivências de uma oficina de interpretação ambiental
}

\author{
João Paulo Carvalho Pinheiro ${ }^{1}$ \\ Clarice Silva Cesário² \\ Ana Carla Neto Ribeiro Carvalho ${ }^{3}$ \\ Renata Barcelos Repolês ${ }^{4}$ \\ Felipe Eugênio Parizzi ${ }^{5}$
}

Resumo: Atividades interpretativas motivam o processo de criação e troca de saberes. Este recurso é muito utilizado em práticas de temática ambiental, já que a sensibilização é o ponto de partida do trabalho. Objetiva-se descrever e compartilhar vivências de uma oficina denominada "Que bicho é esse?", que desperta a atenção para características das diferentes espécies da fauna silvestre local. No período de 12 meses, a oficina foi aplicada 21 vezes, atendendo a 728 estudantes de diversas idades e instituições. Todos os depoimentos recolhidos dos participantes apontaram boa avaliação. Trata-se de um instrumento facilitador ao sistema de ensino escolar e a programas de educação ambiental.

Palavras-chave: Experiência Ecológica; Animais; Vocalização.

\footnotetext{
1 Universidade Federal de Viçosa. E-mail: joaopaulo.carvalho@hotmail.com

2 Universidade Federal de Viçosa. E-mail: claricesilvacesario@gmail.com

3 Universidade Federal de Viçosa. E-mail: repoles_bio@hotmail.com

${ }^{4}$ Faculdades Integradas de Cataguases/Unis. E-mail: anacarla.neto.bio@gmail.com

5 Instituto Estadual de Florestas. IEF/MG. E-mail: felipe.parizzi@meioambiente.gov.br
} 


\section{Introdução}

A necessidade de sensibilizar as pessoas sobre os impactos ambientais causados pela ação do ser humano é urgente. Programas de educação e interpretação ambiental são grandes aliados neste processo, quando realizados sob uma perspectiva social, cultural, econômica e ecológica. Para enfrentar esse desafio deve-se lançar mão de instrumentos pedagógicos menos ortodoxos e mais vivenciais. Eles estimulam a reflexão acerca do cenário ambiental contemporâneo com criatividade e de forma atrativa, possibilitando a formação de uma nova ética.

A interpretação ambiental obtém êxito quando possui uma temática bem estabelecida, e quando é criteriosamente organizada e composta de atividades provocantes, diferenciadas e prazerosas. Algumas unidades de conservação realizam passeios em trilhas e outras atividades recreativas que, em geral, não são elaboradas em torno de temas interpretativos. Apesar de gerarem bemestar, atividades que abstêm desta característica não proporcionam resultados duradouros e, consequentemente, não contribuem na formação de valores sólidos. Estes valores são interpretados a partir da revelação de verdades escondidas por detrás de manifestações simples, capazes de capitalizar a curiosidade do visitante para o enriquecimento da sua mente e do seu espírito (TILDEN, 1977).

A implantação de programas de educação ambiental pode auxiliar no melhor relacionamento das pessoas com os recursos naturais de sua região, a partir do conhecimento do seu valor e da importância de mantê-los em equilíbrio. Trata-se de uma ferramenta valiosa, que apresenta grande potencial para ser acrescida às atividades educativas em escolas e Unidades de Conservação. Além disso, estes programas podem ser realizados com todos aqueles que se relacionam direta ou indiretamente com os ambientes selvagens.

O contato direto com o recurso que está sendo interpretado instiga a vivência de novas experiências e revela significados através do uso de objetos originais (BEDIM, 2004). A aproximação entre conteúdos abordados em sala de aula com aqueles possíveis de serem tratados nestes ambientes, viabilizam a realização de atividades que dinamizam, motivam e facilitam a aprendizagem, tanto do professor quanto dos estudantes (CARREIRO et al., 2009).

Buscou-se criar uma oficina interpretativa que explorasse questões acerca da fauna silvestre e que pudesse ser aplicada tanto em ambientes formais como em não formais. Objetivou-se proporcionar vivências que aguçassem o olhar dos participantes para a (re)descoberta de detalhes sutis da natureza, de maneira instigante, surpreendente e divertida, a partir de métodos diferenciados e não convencionais. Além disso, objetivou-se também avaliar as experiências do público-alvo, após um ano de sua aplicação, e descrever todas 
as etapas da oficina, para que possa ser replicada por outras equipes e em outros ambientes.

\section{METODOLOGIA}

Para melhor divulgação desta oficina, serão descritas todas as suas etapas, discriminando o material, o desenvolvimento e as condutas do monitor, necessários para a execução de cada uma delas, além de uma breve análise e alguns depoimentos obtidos dos participantes após a realização das atividades propostas.

A oficina "Que bicho é esse?" foi elaborada no ano de 2012 na Estação Ecológica Água Limpa/Instituto Estadual de Florestas (EEAL/IEF), uma Unidade de Conservação (UC) de cerca de 70 hectares de Mata Atlântica, um local modelo para a idealização e execução de atividades de educação e interpretação ambiental, devido a sua boa infraestrutura, equipe treinada e proximidade com o centro urbano e rural do município de Cataguases.

Trata-se de uma oficina realizada em várias etapas, o que permite sua aplicação tanto em ambientes formais quanto não formais, com disponibilidade variável de infraestrutura. Estas etapas foram programadas devido às constantes limitações observadas no cotidiano da equipe, como: impossibilidade de deslocamento do público até a UC, pouco tempo disponível pelos participantes, restrições diversas do público-alvo e condições meteorológicas desfavoráveis.

Recomenda-se realizar esta oficina para no máximo 30 pessoas de quaisquer idades, assegurando-se alterações de conteúdo e linguagem, conforme as demandas do público e os objetivos que se pretende alcançar. Um roteiro pré-estabelecido deve ser adotado para que as expectativas do participante e os propósitos educativos da EEAL e do solicitante sejam atendidos. Este roteiro é dividido nas seguintes etapas: recepção/preparação, desenvolvimento, trilha, troca de experiências e encerramento.

\section{Recepção / Preparação}

Os intérpretes/monitores ambientais acompanham os participantes em uma caminhada, desde a portaria da EEAL até o centro de visitantes, dando boas vindas e apresentando a UC. Nesta oportunidade, é fundamental a boa intervenção do monitor, que deve incentivar o grupo a se sentir parte integrante daquele ambiente. Todos dirão seu nome, mas serão preparados para, em pouco tempo, serem renomeados como novos seres, a partir do momento em que adentraram na mata. Na chegada, cada um recebe um "Cartão de fauna" (Figura 1), que será o marco para a sua nova apresentação e seu (re) conhecimento. 


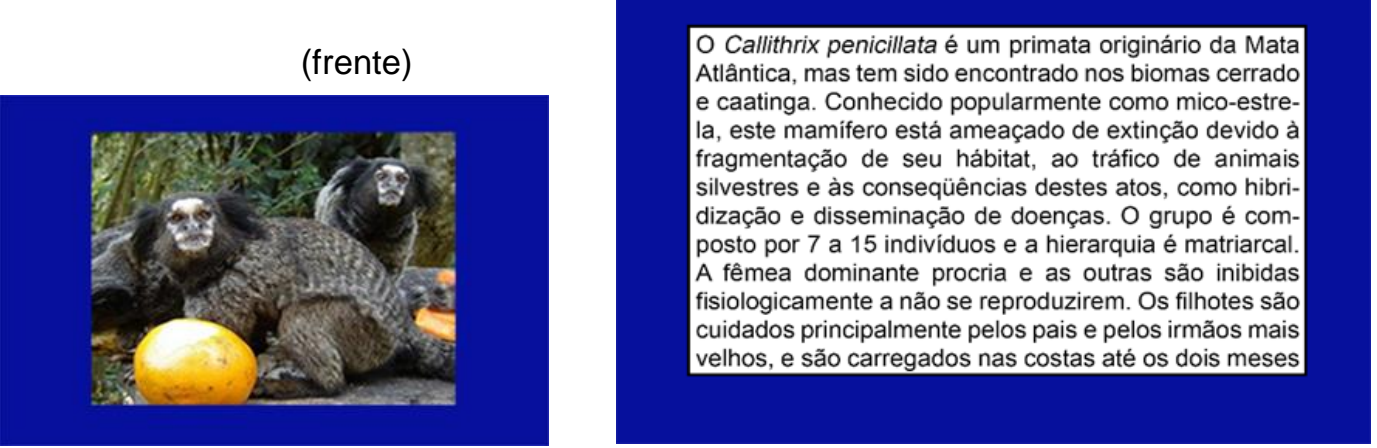

Figura 1: Esquema representativo de cartões de fauna, utilizados na etapa de recepção/preparação dos participantes para que eles se (re) apresentem.

\section{Cartões de Fauna}

MATERIAL: Para esta dinâmica, são necessários cartões de papel de material rígido de $15 \mathrm{~cm}$ de comprimento por $10 \mathrm{~cm}$ de largura. Em uma das faces, coloca-se uma fotografia de um animal da fauna local e, na outra, informações sobre esse animal, como: nome científico, nome popular, categoria de ameaça, características biológicas (reprodução, comportamento, habitat, alimentação, etc.), características culturais (se faz parte do folclore, de crendices, do conhecimento popular, dentre outros.). É importante que nesta etapa sejam utilizadas imagens e informações adequadas, atrativas e direcionadas ao público-alvo.

DESENVOLVIMENTO: Peça que os participantes se organizem em um círculo e distribua um cartão de fauna por pessoa. Explique que se trata do novo indivíduo no qual a pessoa estará se transformando. Instrua os participantes a lerem as informações contidas no cartão, em silêncio, e a se familiarizarem com a sua nova imagem. Cerca de dois minutos após a instrução, diga que todos irão se apresentar novamente, dizendo o seu nome e as características que mais acharam interessante, usando a primeira pessoa do singular. Oriente-os a não lerem os cartões enquanto se apresentam, mas apenas dizerem o que lembram. Inicie você (monitor) a sua apresentação, de maneira descontraída e divertida, representando, quando possível, as características do animal. Exemplo: Meu nome é Maria Bicho-preguiça, sou um animal difícil de ser visualizado porque me camuflo na copa das árvores, graças aos meus movimentos lentos e às algas que vivem no meu pelo, conferindo coloração esverdeada ao meu corpo, (...). Neste caso você pode falar bem devagar, para remeter-se à lentidão do animal, além de fazer alguns movimentos com o braço, como se fosse um bichopreguiça ao se movimentar nas copas das árvores.

RESULTADO ESPERADO: Esta é uma atividade irreverente que permitirá maior aproximação do público com o monitor e com o ambiente. A descontração inicial garantirá que os participantes tenham mais liberdade para se expressarem e para expressarem suas opiniões durante toda a oficina. Esta dinâmica introduz informações que serão utilizadas no decorrer da oficina e deixa os participantes mais animados e com maior expectativa para as atividades seguintes. 


\section{Desenvolvimento}

Os monitores/intérpretes ambientais encaminham os participantes para o local de projeção de slides para realizar a etapa de demonstração de imagens e sons dos animais. Esta etapa deu origem ao nome da oficina, pois, a partir das projeções, o monitor pergunta aos participantes "Que bicho é esse?". Este local pode ser uma sala de aula, um anfiteatro, ou até mesmo ambientes abertos que contenham sombra e disponibilidade de energia elétrica.

MATERIAL: um projetor de slides, uma tela para projeção, um computador e o documento contendo as imagens e os sons dos animais. As imagens dos animais e os sons que eles emitem podem ser adquiridos gratuitamente a partir de pesquisas feitas na internet em sites de busca.

DESENVOLVIMENTO: Projete os slides contendo imagens e reproduções de vocalizações das espécies da fauna silvestre local (Figura 2). Instigue os participantes a adivinharem o nome popular dos animais, baseando-se em pistas fornecidas pela morfologia (imagem do animal) ou pelos sons que eles emitem (reproduções das vocalizações). Depois de descobrirem de que animal se trata, apresente algumas informações sobre o mesmo, como o nome científico, algumas características biológicas, ou conforme o seu objetivo. Em um segundo momento, exiba sons de agregados de anuros. Desafie os participantes a descobrirem quantas vocalizações diferentes são emitidas e de quais espécies se tratam, levando em consideração o conhecimento adquirido até 0 momento. Finalize esta etapa da oficina, motivando os participantes a encontrarem os animais camuflados em seu ambiente a partir de imagens projetadas.

RESULTADO ESPERADO: Nesta etapa, os participantes relatam suas dúvidas e compartilham suas estórias. Eles também desenvolvem maior curiosidade e atenção para os detalhes mais minuciosos da natureza. Esta experiência prepara-os para a próxima etapa da oficina, que é a observação e a interpretação dos detalhes durante a trilha guiada.

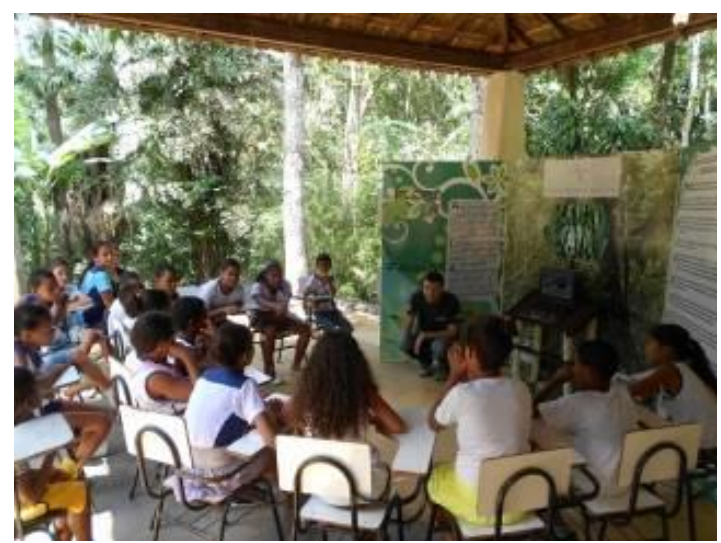

Figura 2: Momento de projeção das imagens e sons de animais silvestres da região na Estação Ecológica Água Limpa, em Cataguases/MG, na etapa de desenvolvimento da oficina "Que bicho é esse?". 


\section{Trilha}

A preparação para esta etapa começa no ambiente da atividade anterior, quando os monitores tecem recomendações de segurança para a realização de trilhas e dicas de como se portar em uma UC. Em seguida, eles são guiados para o início da trilha e se inicia essa etapa. Os temas abordados durante a trilha são, muitas vezes, pré-estabelecidos pelo solicitante da visita, no momento do agendamento. Neste caso, adicionam-se as informações desejadas ao roteiro das atividades. A trilha possui pontos de parada estratégicos e pré-estabelecidos, para que se discuta o conteúdo necessário e para que alguns detalhes já conhecidos pelos monitores recebam a atenção dos participantes.

MATERIAL: equipamentos auxiliares para a visualização de animais ou de marcas deixadas por eles no ambiente (lupa e binóculos); material para aguçar a observação e a curiosidade (animais taxidermizados, peças anatômicas, moldes de pegadas, pelos, crânios e fezes de animais silvestres); material para atividades complementares (espelhos, cartolinas com fotografias de animais e "espelho mágico"- trata-se de um espelho grande que será colocado em uma superfície, apontando para as copas no final da trilha).

DESENVOLVIMENTO: Distribua os binóculos e as lupas entre os participantes, inicie a trilha com o grupo e os instigue a observar os detalhes da natureza. No percurso, esclareça eventuais dúvidas e fale sobre algumas curiosidades dos locais por onde passam. Nos pontos de parada programados, discuta com os participantes as informações direcionadas sobre a fauna, sua interação com o ambiente e os demais conceitos desejados pelo solicitante da oficina. Distribua, nestes pontos, os materiais para aguçar a observação e a curiosidade dos participantes e os materiais para atividades complementares (veja algumas opções em "material") (Figuras 3A e 3B). Aproveite para dispor os materiais, seguindo uma linha de raciocínio, para que nenhuma informação seja esquecida. Também escolha os pontos, levando em consideração os recursos já existentes na trilha, como, por exemplo: placas, marcas deixadas por animais, arbustos e árvores silvestres com frutos consumidos pelos animais da região, ninhos, teias, dentre outros. Durante o percurso, em um trecho plano e sem obstáculos, disponha os participantes em fila indiana. Recolha os materiais que eles carregam e distribua um espelho para cada um. Solicite que o segurem com a mão direita, apontando para o próprio rosto. A mão esquerda deve ser colocada no ombro da pessoa da frente. Posicione-se no início da fila e distribua outros monitores em locais equidistantes na fila, todos sem espelho. Comece a puxar a fila, lentamente, e peça aos participantes que se deixem guiar pelo colega da frente, enxergando o que o espelho lhe mostrar. Peça para que eles mudem o espelho de posição, apontando-o para as copas das árvores, para o chão, para os colegas que estão atrás, etc. Para finalizar esta etapa, recolha os espelhos e vá até o final da trilha. Sugira que cada participante passe pelo "espelho mágico" e que observe todos os integrantes 
do meio. Neste momento, ele verá sua imagem refletida em meio às copas das árvores.
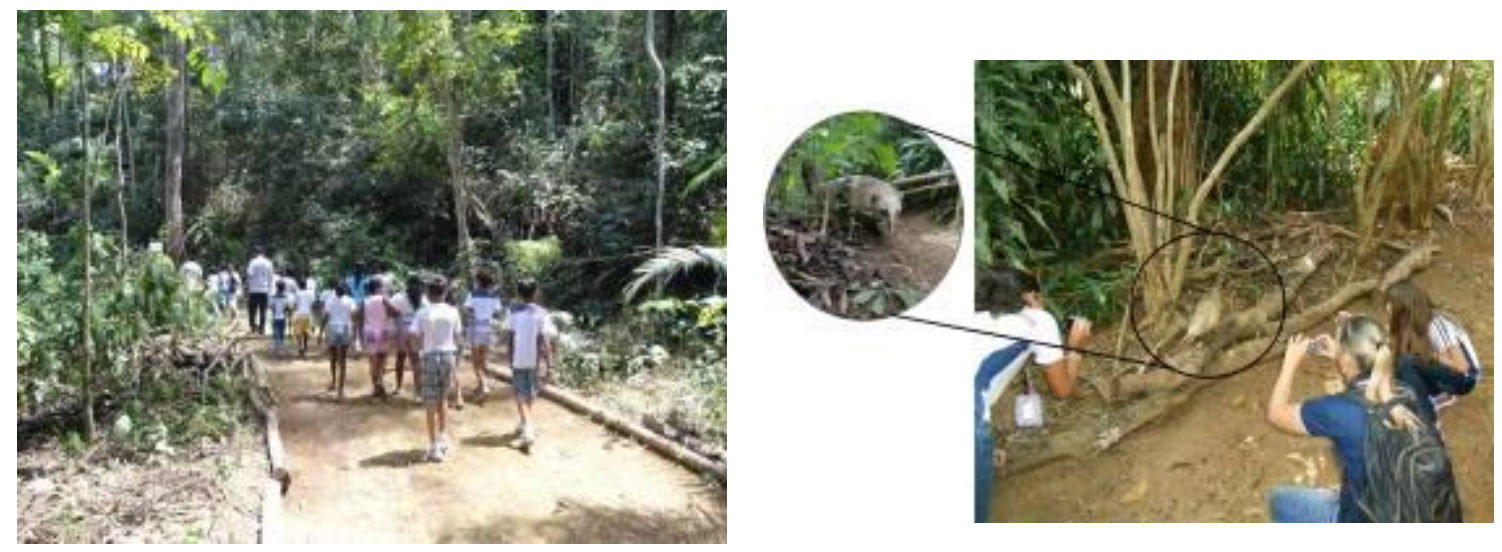

Figuras 3A e 3B: Participantes da oficina caminhando pela trilha interpretativa e se deparando com os animais taxidermizados dispostos nos pontos de parada na Estação Ecológica Água Limpa, em Cataguases/MG.

RESULTADO ESPERADO: Esta bela experiência permite a interação dinâmica, educativa e descontraída com o meio. O integrante definitivamente se enxerga como parte desse meio, tornando-se mais sensível e observador. As informações direcionadas são absorvidas com naturalidade e de forma não ortodoxa.

\section{Troca de experiências}

Após a trilha, os participantes são convidados finalizarem as atividades em um ambiente previamente escolhido, para relatarem as experiências vividas durante todas as etapas da oficina. Este é um momento crucial para que as vivências sejam eternizadas e para que o processo de sensibilização seja multiplicado por eles em outros ambientes. É recomendável que o monitor retome todas as etapas e os momentos mais marcantes da oficina, para que as lembranças deem lugar às opiniões e à troca de saberes, tanto dos participantes quanto dos monitores. Em seguida, é realizado um debate que aborde um tema ambiental da atualidade ou de escolha do solicitante da visita (Figura 4). O debate permite a construção de princípios relacionados a direitos e deveres do cidadão além do respeito ao meio ambiente. Ao final, convide os participantes ao relaxamento e à meditação, de olhos fechados e em silêncio, ouvindo o som da natureza. 


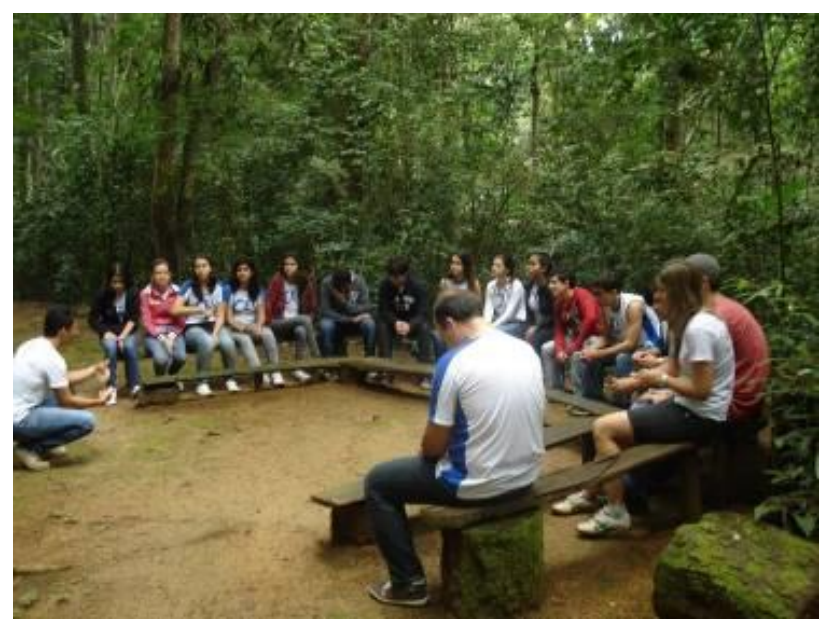

Figura 4. Momento de descontração e de debate, etapa de troca de saberes, na sala ao ar livre da Estação Ecológica Água Limpa, em Cataguases/MG

\section{Encerramento}

No encerramento da oficina, são aplicadas atividades que materializem as experiências vivenciadas, na forma de desenhos, colagens e pinturas em folhas de ofício (Figura 5). Este produto constitui uma boa forma de reviver o momento da interpretação ambiental. As obras produzidas são levadas para casa, como lembrança.

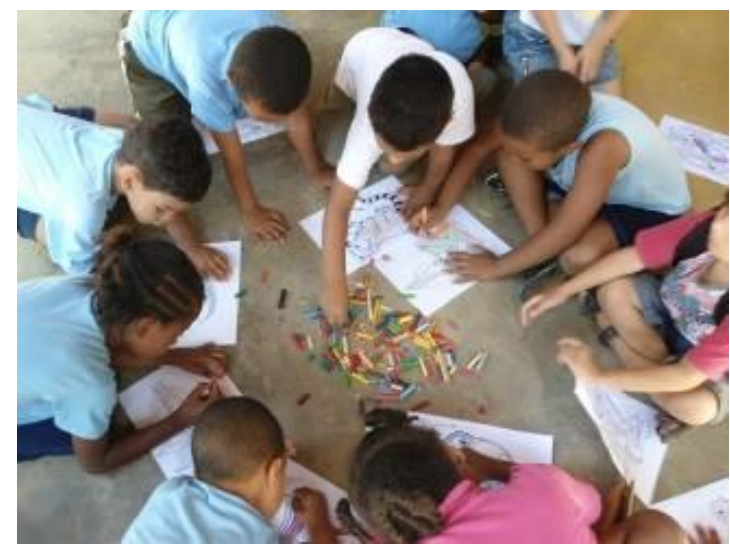

Figura 5: Desenho representativo da etapa de encerramento.

Após a aplicação da oficina são coletados, sistematicamente, depoimentos escritos pelos responsáveis ou solicitantes da visita, para se contabilizar as impressões acerca das atividades e investigar se as expectativas foram atendidas. Estes dados foram analisados de forma quantitativa e em caráter descritivo. A abordagem qualitativa também foi contemplada, pois ela captura variados significados sobre as experiências vividas no ambiente, auxiliando na compreensão das relações entre pessoas, seu contexto e suas ações (ANDRÉ, 1983). 


\section{RESULTADOS E DISCUSSÃO}

Durante os meses de outubro/2012 e outubro/2013 a oficina "Que bicho é esse?" foi aplicada 21 vezes, atendendo a um público de 728 estudantes de 14 instituições (Quadro 1).

Quadro 1. Público e instituições atendidas pela oficina "Que bicho é esse?"

\begin{tabular}{|l|c|r|}
\hline \multicolumn{1}{|c|}{ Instituições / Escola } & Municipio & Público Atendido \\
\hline Escola Municipal Pequeno Principe & Cataguases & 27 \\
\hline Escola Estadual Santo Antonio & Mirai & 77 \\
\hline Escola Técnica de Formação Gerencial - Sebrae & Cataguases & 27 \\
\hline Escola Municipal Judith Lintz Guedes Machado & Leopoldina & 20 \\
\hline Escola Estadual Clóves Salgado & Cataguases & 87 \\
\hline Escola Estadual Sebastião Silva Coutinho & Leopoldina & 45 \\
\hline Escola Estadual Lysis Brandão da Rocha - Caic & Cataguases & 46 \\
\hline Projovem Adolescente Cataguases & Cataguases & 52 \\
\hline Casa da Criança & Cataguases & 69 \\
\hline Escola Estadual Omar Resende Peres & Leopoldina & 87 \\
\hline Colégio Soberano & Cataguases & 80 \\
\hline Centro Educacional Conhecer & Leopoldina & 12 \\
\hline Instituto Metodista Arca de Noé & Leopoldina & 65 \\
\hline Universidade Federal de Viçosa & Viçosa & 34 \\
\hline
\end{tabular}

À análise dos depoimentos, observou-se a aprovação da oficina por todos os responsáveis ou solicitantes da visita, que destacaram a agradabilidade da trilha, o caráter informativo das atividades e a diversão, como características mais marcantes. O último depoimento demonstra que a variação na aplicação desta oficina, quando realizada dentro de ambientes formais, também é satisfatória:

"Adoramos o passeio, os assuntos abordados foram ao encontro do que estamos estudando em sala de aula, foi enriquecedor para todos nós." (C. R. T.)

"Foi agradável e proveitoso. O assunto foi enriquecedor e dentro do contexto. Só temos a agradecer a disponibilidade dos instrutores." (J. F.)

"Foi uma atividade legal e muito divertida." (E. S.)

" $A$ atividade realizada em nossa escola foi muito positiva. Através de vídeos e de um material simples o monitor conseguiu prender a atenção dos alunos, entrou em sintonia com eles e pode mostrar a diversidade dos seres vivos, tornando a apresentação um momento de aprendizado e interação." (R. P. R) 
Estes relatos parecem estar vinculados ao fato de que o conhecimento passado em sala de aula, relacionado a temas ambientais, é distanciado das vivências ao ar livre. Isso torna as atividades em ambientes formais frequentemente entediantes. Levar alunos a locais como a EEAL é uma forma inovadora de aprender e reafirma a necessidade da aplicação de novas maneiras de se ensinar conteúdos sobre as Ciências Naturais. As experiências com o ambiente facilitam o entendimento da complexidade das interações que existem na natureza, inserindo o ser humano como parte integrante do ecossistema. Por isso a oficina demonstrou ser um recurso metodológico de aprendizagem que supera as formas de ensino restritas à simples memorização e verticalização de conceitos. Ela permeia a troca e a articulação de saberes a partir de atividades interdisciplinares e vivenciais.

Os alunos participantes demonstraram interesse pelas atividades propostas, atenção às recomendações e curiosidade para a busca do conhecimento. As respostas aos estímulos fornecidos foram crescentes e amadureceram à medida que se disponibilizavam mais informações sobre os animais e seu meio. Puderam-se ouvir muitos relatos de satisfação no decorrer da oficina. Relacionou-se esse fato à sensação de conforto, relaxamento e prazer que a mata oferece, sobretudo em atividades de trilha aliadas à interpretação ambiental. As cores vivas, os odores diferentes, os sons incomuns ao cotidiano urbano e as texturas abundantes parecem despertar a empatia dos participantes pela natureza.

Os momentos em que os participantes são instigados a relatar suas sensações e experiências são muito produtivos e fortalecem a construção do saber. Consideramos que, nesta oficina, os alunos tiveram a oportunidade de serem sujeitos de sua aprendizagem, porque incorporaram seus referenciais, a sua linguagem e os seus conceitos ao que Ihes era apresentado. Este processo é importante para que cidadãos de qualquer idade se apropriem de determinado conhecimento. Um fator determinante para que isso ocorra é o treinamento e o preparo dos intérpretes/monitores e dos professores. Incentivar a participação de maneira natural e fluida requer disposição e empolgação, para que os alunos não se sintam envergonhados, e sim, seguros para se expressarem livremente.

\section{CONSIDERAÇÕES FINAIS}

Atividades interpretativas, vivenciais e com temas bem definidos podem garantir resultados satisfatórios em programas de educação ambiental. As experiências obtidas com a aplicação da oficina "Que bicho é esse?" demonstraram que criatividade, integração, participação e acesso a áreas verdes são ferramentas para um melhor aprendizado e instauração de novas formas de encarar a realidade ambiental.

Esta oficina pode servir de modelo para ser aplicada e integrada ao plano de manejo de outras Unidades de Conservação, vista sua eficácia como 
instrumento facilitador de atividades educativas. Espera-se que ela incremente os programas de educação ambiental dessas áreas, as quais são vitais para a manutenção do conhecimento da biodiversidade local e regional.

É de suma importância que este tipo de atividade esteja disponível para outras frações da sociedade, que não somente as escolas, como, por exemplo, associações de bairro, sindicatos rurais e população de maneira geral. É preciso democratizar o acesso a estas vivências, pois elas conseguem de forma simples, descontraída e prazerosa, promover a sensibilização das pessoas.

\section{REFERÊNCIAS}

ANDRÉ, M. E. D. A. Textos, contextos e significados: Algumas questões na análise de dados qualitativos. Cadernos de Pesquisa, São Paulo, no 45, p. 6671, mai. 1983.

BEDIM, B. P. Trilhas interpretativas como instrumento pedagógico para a educação biológica e ambiental: reflexões. Universidade Federal de Ouro Preto. Disponível em: http://pt.scribd.com/doc/203907260/TRILHASINTERPRETATIVAS\#download. Acessado em 21/02/2014

SANTOS, C. M.; LOPESE. A. M.; PASSIPIERI, M.; DORNFELDC. B. Oficina de interpretação ambiental com alunos do ensino fundamental na "Trilha do Jatobá" em Ilha Solteira, SP. Revista Eletrônica de Educação, v. 6, noำ 2, p. 271-287, nov. 2012.

CARREIRO, P.; TABANEZ, M. F.; SOUZA, S. A. Contribuições do roteiro interpretativo da Trilha das Árvores Gigantes às práticas pedagógicas de professores que visitam o Parque Estadual de Porto Ferreira. Instituto Florestal, Série Registros, São Paulo, o 40, p. 95-102, jul. 2009.

Projeto Doces Matas. Brincando e aprendendo com a mata: manual para excursões guiadas. Belo Horizonte, 2002.

Projeto Doces Matas/Grupo Temático de Interpretação Ambiental. Manual de Introdução à Interpretação Ambiental. Belo Horizonte, 2002.

SENICIATO, T.; CAVASSAN, O. Aulas de campo em ambientes naturais e aprendizagem em Ciências - Um estudo com alunos do ensino fundamental. Ciência e Educação, vol. 10, nº1, p. 133-147, 2004.

TILDEN, F. Interpreting our heritage. $3^{\mathrm{a}}$ ed. The University of North Carolina Press. 1977. 